\title{
An LFG analysis of pronominal binding in Mandarin Chinese
}

\author{
Hongyuan Dong*
}

\begin{abstract}
Pronominal binding in Mandarin Chinese can be affected by different embedding verbs. For example, verbs like "gănxiè" ("to thank") impose a negative constraint that requires the embedded subject pronoun not to be bound by the matrix subject DP. On the other hand verbs like "zhīdào" ("to know") do not have such a requirement, thus conforming to the Binding Principle B. Importantly, binding relations of pronouns in sentences with verbs like "gănxiè" ("to thank") cannot be accounted for within the framework of the standard Binding Theory. It cannot be explained by the control theory that involves PRO, either, although there is indeed some similarity between such negative constraints and control structures. Therefore I propose to add a negative constraint in the lexical entries of such verbs, based on how control is handled in LFG. This proposal has both theoretical and application advantages.
\end{abstract}

Keywords. binding principles; pronominal binding; control theory; LFG; Chinese.

1. Introduction. Pronominal binding in general is less complicated within the framework of the Binding Theory, compared to the complexity of anaphoric binding in many different languages. However, data from Mandarin Chinese pose some theoretical problems for the Binding Principle B. Specifically, different embedding verbs affect the binding relations between a pronoun in the embedded clause and the potential binder in the matrix clause. Some verbs, e.g. "gănxiè" ("to thank"), do not allow a pronoun in the embedded subject position to co-refer with the matrix subject DP. On the other hand, other types of verbs, e.g. "zhīdào" ("to know"), do not have such a constraint. The Binding Principle B can readily account for data with verbs like "zhīdào", but not with verbs like "gănxiè". This problem seems to suggest that pronominal binding should take more lexical information into consideration. This is exactly the focal point of this current study.

The paper is organized as follows. In section 2, I describe the relevant data in more detail. In section 3, the theoretical issues will be discussed, especially with regard to the applicability of the Binding Principle B. My main proposal will be made in section 4, in which I propose to add more information to the lexicon of verbs such as "gănxiè", in the form of a negative constraint, based on how similar phenomena of control are treated in Lexical Functional Grammar (LFG). In the conclusion in section 5, I will discuss the advantages of my proposal, and illustrate directions for further research.

2. Relevant Data. The key examples, such as shown in (1), are originally discussed in Dong (2002), and subsequently in Shen and Dong (2004), Hu and Shi (2006).

Mandarin Chinese (Shen and Dong 2004: 21)
Xiăo Wáng gănxiè [IP tā $*_{i j}$ zuò de dù̀ ]
Xiao Wang thank he do COMP correct
'Xiao Wang ${ }_{i}$ thanks that he $*_{i j}$ did the right thing.'

\footnotetext{
* I would like to thank the audience at the Department of Linguistics, Stony Brook University on October 16, 2015, especially Dr. Jiwon Yun and Dr. Thomas Graf for valuable comments. Comments from various people at the LSA meeting have also been very helpful. Author: Hongyuan Dong, George Washington University (hdong@gwu.edu).
} 
The word "tā" is a third-person singular pronoun. There is no gender distinction in the pronoun system of Chinese, although recent innovation in writing has resulted in two different written symbols for the third person singular pronoun based on the gender distinction. The "de" introduces a complement that describes the action denoted by the preceding verb, hence the label COMP. In example (1), "tā" is in the subject position of the embedded clause, and it cannot be bound by the DP "Xiăo Wáng" in the matrix subject position. Note that the English translation in (1) is not quite grammatical in English, but it preserves the original structure of the Chinese example. A more felicitous English translation could be "Xiao Wang thanks him for doing the right thing". Here in the English translation the embedded clause is a non-finite clause. But whether the embedded clause in (1) in Chinese is also a non-finite clause is the most important issue here, which we will pick up later in section 3.

If we vary the configuration by putting the pronoun and its potential binder in other positions, e.g. in the object position, in the specifier position of a DP, the situation becomes more complicated, as discussed in Dong (2002), and Shen and Dong (2004) in much detail. In example (2), the pronoun "tâ" is in the object position of the embedded clause, and it cannot co-refer with "Xiăo Wáng" in the specifier position of the matrix subject DP. The symbol ASP stands for "aspect marker". More discussion is available in section 3.

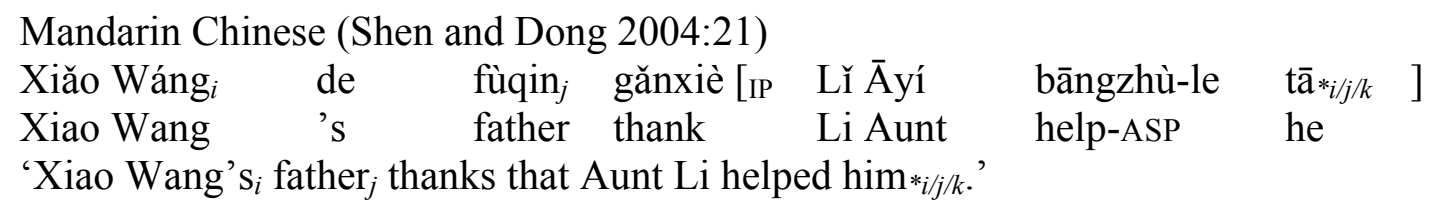

If the pronoun is in the specifier position of the embedded subject DP, it cannot co-refer with the DP "Xiăo Wáng" in the specifier of the matrix subject DP, as shown in example (3). Although the choice of words strongly favors an interpretation where the schoolmate is Xiao Wang's schoolmate, it is nonetheless not possible in (3) and consequently it has to be Xiao Wang's father's schoolmate here.

(3) Mandarin Chinese (Shen and Dong 2004: 21)

Xiăo Wáng ${ }_{i}$ de fùqin $_{j}$ gănxiè [IP tā $_{* i j / k}$ de tóngxué zhăodào-le chēzi ]

Xiao Wang 's father ${ }_{j}$ thank he 's schoolmate find-ASP vehicle

'Xiao Wang's $s_{i}$ father ${ }_{j}$ thanks that his $*_{i j / k}$ schoolmate found the vehicle.'

If the pronoun is in the specifier position of the embedded object DP, it cannot co-refer with the DP "Xiăo Wáng" in the specifier position of the matrix subject DP, as shown in (4).

(4) Mandarin Chinese (Shen and Dong 2004:21)

Xiăo Wáng ${ }_{i}$ de fùqin $_{j}$ gănxiè [IP Ľ Ǎyí zhăodào-le tā $*_{i j / k}$ de chēzi ]

Xiao Wang 's father thank Li Aunt find-ASP he 's vehicle

'Xiao Wang's $s_{i}$ father ${ }_{j}$ thanks that Aunt Li found his $*_{i j / k}$ vehicle.'

In order to substantiate these generalizations, Dong (2002) searches a corpus ${ }^{1}$ of Modern Standard Chinese for sentences that contain the word "tā" in an intra-sentential co-reference configuration. Altogether about 150 sentences are found and there are 30 sentences that have similar

\footnotetext{
${ }^{1}$ This is the corpus of Modern Standard Chinese maintained by Professor Guo Rui of the Department of Chinese Language and Literature, Peking University. The sources include representative writings from such major writers as Lao She, Wang Shuo and etc.
} 
configurations to the examples (1)-(4) above. The binding relations in all of these 30 sentences conform to the constraints as described above.

However, Hu and Shi (2006), drawing on Reinhart and Reuland's (1993) theory, argue that pronominal binding should be explained in terms of theta structure of the semantic predicate, rather than argument structures. They do not agree with the grammatical judgments with respect to the binding relations in examples (2), (3) and (4), and argue that it is possible to get interpretations that are contrary to the constraint shown here. But they agree with the grammatical judgment in example (1). Thus it seems that there are still disagreements as to whether examples (2), (3) and (4) show the binding relations as indicated here.

I will now focus on example (1), since it is a phenomenon with a wider consensus among researchers in terms of its grammaticality judgment. First, I want to figure out what theoretical issues example (1) poses and how it can be accounted for, and then when the issues regarding examples (2), (3), and (4) become more clear, my proposal here can be extended to cover these further examples if Shen and Dong (2004) are correct, or if Hu and Shi (2006) are correct, then there will be no need to extend my current proposal, because the generalizations here in examples (2), (3) and (4) would be irrelevant.

Now let's contrast example (1) with example (5), in which the only difference is the embedding verb, i.e. "zhīdào" ("to know"), instead of "gănxiè" ("to thank"), and everything else is exactly the same. The negative constraint in (1) disappears in example (5). It is possible for the embedded subject pronoun "tầ" to co-refer with the matrix subject DP "Xiăo Wáng", and it can also refer to someone other than Xiao Wang.

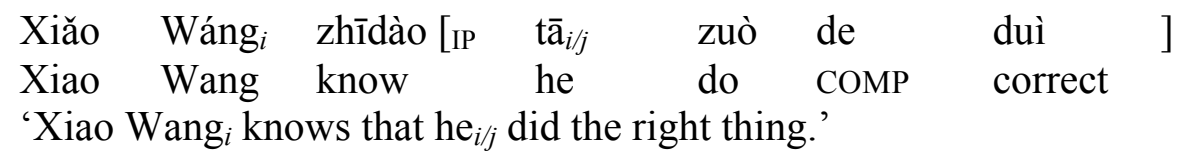

Since the only difference is in the embedding verbs used in these two examples, the most likely explanation is that these verbs pose different constraints on the interpretations of binding relations. Actually verbs like "gănxiè" and "zhīdào" are not the only such embedding verbs.

They represent two subcategories of verbs. Here are a few more examples to illustrate this point.

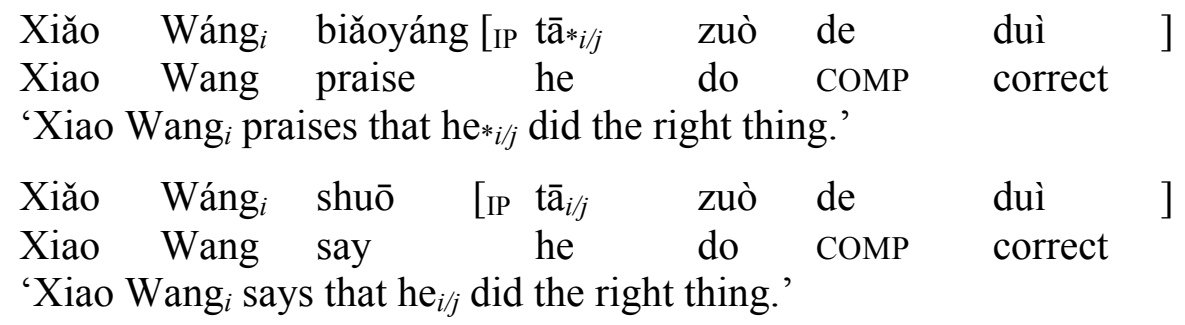

The verb "biăoyáng" ("to praise") is similar to "gănxiè", and in example (6), the pronoun "tā" in the embedded subject position cannot co-refer with the matrix subject DP "Xiăo Wáng". The verb "shuō" is similar to the verb "zhīdào", and in example (7), the pronoun "tā" in the embedded subject position can co-refer with the matrix subject DP "Xiăo Wáng". According to Dong (2002) and Shen and Dong (2004), verbs like "gănxiè" and "biăoyáng" denote actions that point "outwards", while verbs like "zhīdào" and "shuō" denote actions that can either point "outwards" or "inwards". They coin the term "vector verbs" for the subcategory of verbs that includes "gănxiè" and "biăoyáng". Now let's simply use the feature [ \pm directional] to label these two types of verbs, as shown in (8). 
Two types of embedding verbs:

[+directional]: "gănxiè", "biăoyáng", and etc.

[-directional]: "zhīdào", "shuō", and etc.

To summarize the data presented in this section, [+directional] verbs do not allow the pronoun in the embedded subject position to be bound by the matrix subject DP. On the other hand, [-directional] verbs do not have such a negative constraint, and it is possible for the pronoun in the embedded subject position to be bound by the matrix subject DP. Now our question is whether such data can be accounted for by resorting to the Binding Principles, especially Binding Principle B, either in its standard version, or in a slightly modified version.

3. Theoretical issues. The Binding Principles (e.g. Chomsky 1981:188) are constraints on the co-reference possibilities for anaphors, pronouns, and R-expressions. They can be formulated as:

The Binding Principles

- Principle A: An anaphor is bound in its governing category.

- Principle B: A pronominal is free in its governing category.

- Principle C: An R-expression is free.

Although there have been many modified versions since Chomsky's (1981) version, e.g. Chomsky (1986), for my purposes here, the version in (9) is sufficient to illustrate the theoreticcal issues raised by example (1). According to these principles, the co-reference relations in the following English examples can be readily explained.
a. $\operatorname{John}_{i}$ likes himself $f_{i / * j}$
b. $\mathrm{John}_{i}$ likes him $*_{i}$.
c. $\mathrm{John}_{i}$ likes $\mathrm{John}_{*}$.

In example (10a), the governing category is the whole IP, and the anaphor "himself" must be co-indexed with the subject DP "John", which c-commands the object DP. Therefore this example conforms to Principle A. In (10b), the configuration is the same but the pronoun "him" cannot be co-indexed with the c-commanding DP "John". This conforms to Principle B. Expressions like "John" are neither anaphors nor pronouns, and they can refer independently of another expression, and therefore they should always be free. This is shown in (10c). Note that the sentence in $(10 \mathrm{c})$ can be fine in a contrastive context, but even in that context, it is not due to binding that the second use of the proper noun "John" refers to the same individual as the first use of the proper noun "John". Thus what we are saying is that proper nouns cannot be bound.

My focus in this paper is Principle B in terms of its applicability to the Chinese examples in (1) and (5). Let's take a look at (5) first. The embedded clause should be the governing category or binding domain of the pronoun "tâ", and within this domain, the pronoun is free. This conforms to the Binding Principle B. Outside this domain, though, we can infer from the formulation of the Binding Principle B, that the pronoun can be bound by the matrix subject DP, which c-commands the pronoun. As we can see, this is indeed possible in example (5). The pronoun "tā" can be co-indexed with the subject "Xiăo Wáng". Now let's look at example (1). According to the Binding Principle B, the pronoun "tâ" should be free in the embedded clause. This is indeed the case here. But outside the binding domain, the pronoun "tā" should be able to co-refer with the c-commanding DP "Xiăo Wáng". But we see that this is not possible in example (1). Thus it seems that the Binding Principle B cannot cover cases like example (1). 
A common objection to my claim is that the Binding Principle B only cares about the binding relations within the binding domain and does not say anything at all outside the binding domain. Consequently, whether "tâ" can or cannot co-refer with the matrix subject DP "Xiăo Wáng" does not matter for the Binding Principle B. However this line of reasoning is very weak. Specifically, the Binding Principle B can also be understood to define the domain in which the pronoun must be free, and if the embedded clause in (1) is the domain as defined in the Binding Theory, then example (1) is problematic for the Binding Principle B, simply because the domain in which the pronoun must be free is not the embedded domain, but the whole matrix clause. Therefore the binding domain for sentences like (1) must the redefined in order to make the Binding Principle B work here. However, since the configuration in (5) is exactly the same as in (1), we cannot redefine the binding domain for (1) without affecting the binding domain for (5). But if we expand the binding domain for (5) to the whole matrix clause, then this will give the wrong prediction that the pronoun "tâ" in (5) must be free within the whole matrix clause. Now we have a dilemma. If we define the binding domain as the embedded clause, then we can use the Binding Principle B to cover cases like (5), but not (1); if we define the binding domain as the whole matrix clause, then the Binding Principle B can cover cases like (1), but not (5).

Dong (2002) and Shen and Dong (2004) propose to take the two types of verbs into account when formulating the rules of pronominal co-reference. Their approach is, strictly speaking, not within the framework of the Binding Theory, but to illustrate how their proposal works, let's translate their proposal into a possible solution within the Binding Theory here. Suppose that we keep the formulations of the Binding Principles as in (9) without any changes. But then we can define two types of binding domains. For [+directional] verbs, the binding domain should be the matrix clause; for [-directional] verbs, the binding domain should be the embedded clause. This solution can cover the examples (1) and (5) here. But it is problematic because we are redefining binding domains for pronouns and we wonder if anaphors should also be similarly affected. There is no evidence that there should be two domain definitions for anaphors depending on the types of verbs used. Note that the Binding Principles capture an interesting parallel property between the binding relations of anaphors and pronouns, i.e. within the same binding domain, anaphors and pronouns have totally opposite binding behavior. If we only redefine the binding domain for pronouns, we are contradicting one of the original motivations for the Binding Principles. Therefore by simply redefining the binding domains, we are only creating new problems to solve. Admittedly, this solution may very well prove to be correct if we find a way to recapture the parallelism behind the original formulations of the Binding Principles within this new approach to binding domain. However I am not sure this will be the best solution. Therefore I will find a different solution, which is sketched later in this paper.

Another objection to my claim that example (1) creates a problem for the original Binding Principle B is that the analysis of the phrase structure in (1) is not correct. Hu and Shi (2006) argue along this line of reasoning that the structure in (1) is actually a control structure with a PRO. According to their proposal, example (1) should rather be analyzed as:

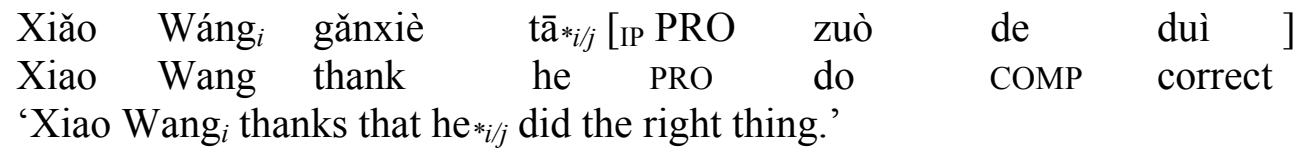

In (11), the binding domain for the pronoun "tâ"” is still the immediate clause that contains it, which now is the matrix clause. According to the Binding Principle B, the pronoun "tä" cannot be bound by the matrix subject DP "Xiăo Wáng", which is exactly the case here. Now recall 
that I have pointed out earlier in section 2 that the translation of example (1) is somewhat problematic in English, and a more felicitous translation would be "Xiao Wang thanks him for doing the right thing", and here a non-finite clause is used. However the key issue is whether the embedded clause in (1) is a non-finite clause. Clearly $\mathrm{Hu}$ and Shi (2006) think so, and similarly Shen and Dong (2004) also assimilate example (1) to a control structure, which they describe as $\left[\mathrm{NP}_{1} \mathrm{~V}_{1} \mathrm{NP}_{2}\left[\mathrm{PRO}=\left(\mathrm{NP}_{2}\right) \mathrm{V}_{2} \mathrm{NP}_{3}\right]\right.$.

However, it is not easy to show for sure whether an embedded clause is finite or non-finite in Chinese, due to the fact that there is no systematic grammatical device to convey tense. Although sentences with the aspectual marker-le often have a past tense interpretation in many cases, such as shown in (12), there is actually no past tense morpheme in such sentences (see Lin 2006 for details). The past tense interpretation of (12) can be specified by using the past time word such as "yesterday", or by a combination of the perfective aspect conveyed by the word -le with reference to the speech time. The symbol CL stands for "classifier".

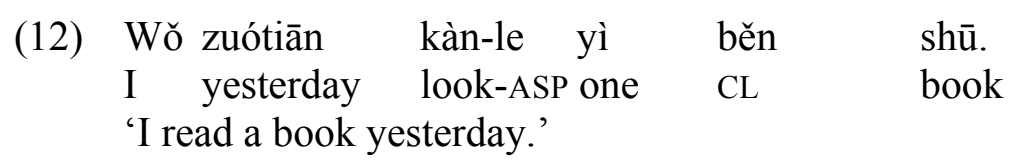

It is possible to add the perfective aspect marker -le to example (1), as shown in (13) here, but it does not prove the embedded clause to be a finite clause, because it can be felicitously translated as "Xiao Wang thanks him for having done the right thing".

(13) Xiăo Wáng gănxiè tā zuò-le duì-de shìing
Xiao Wang thank he do-ASP correct thing
'Xiao Wang ${ }_{i}$ thanks that he $*_{i j}$ did the right thing.'

Similarly, let's consider the verb "ràng" ("to ask, to command"), and it is also compatible with the aspect marker-le, as shown in (14).

(14) Xiăo Wáng ràng tā zuò-le gōngkè jiù shuijiào.
Xiao Wang ask he do-ASP homework then sleep
'Xiao Wang ${ }_{i}$ asks him $*_{i j}$ to do homework and then go to bed.'

It should be pointed out that if there are non-finite clauses in Chinese, they should look more like (14) with a typical control verb, such as "ràng". However since both example (13) and example (14) are compatible with the aspect marker -le, we still need to find a real tense morpheme in Chinese to test whether there is a difference between examples (13) and (14).

Although the past tense is not grammatically expressed in Chinese, Hsieh (2002) argues that Chinese does have grammatical tense and the auxiliary verb "hui" ("will") marks relative future tense. If indeed "hui" expresses tense, we may test its compatibility with verbs like "gănxiè" and "ràng". Examples (15) and (16) show that there is clearly a distinction.

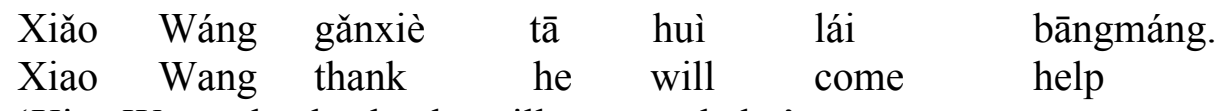

'Xiao Wang thanks that he will come to help.'

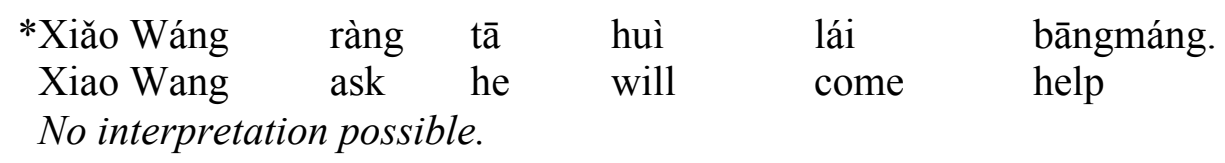


In (15), the verb "gănxiè" is very well compatible with the tense marker "huì", but example (16) shows that the verb "ràng" is not compatible with "huil" and in fact there is no possible interpretation at all for such a sentence. Now if there is indeed a distinction between non-finite and finite clauses on the one hand, and between control structure and other types of structures on the other hand, verbs like "ràng" are typical control verbs and they take a non-finite clause, while verbs like "gănxiè" are not control verbs and they take a finite clause. Therefore it is not possible to account for example (1) within the Binding Principles and the control theory.

To sum up this section, we start from the contrast between verbs like "gănxiè" and "zhīdào". It is shown that with "gănxiè" as the matrix verb, a pronoun in the embedded subject position cannot be bound by the matrix subject DP, thus contradicting the standard version of the Binding Principle B, but with "zhīdào" as the matrix verb, there is no such contradiction. Although this issue would be simply solved if verbs like "gănxiè" are control verbs, as argued by Shen and Dong (2004), and Hu and Shi (2006), I have shown that "gănxiè" is not a control verb, because it is compatible with the tense marker "huì", while verbs like "ràng" are possibly control verbs because they are incompatible with the tense marker "hul". On the other hand, although example (1) could be accounted for by resorting to two different binding domains for [+directional] verbs and [-directional] verbs, such a solution would fail to capture the original parallel binding properties between anaphors and pronouns. No solution so far has been proven to be good enough. I give a different solution in the next section from a lexical perspective.

4. A lexical approach. I have shown that pronominal binding in Mandarin Chinese is affected by different embedding verbs. Thus it points towards a lexical approach to binding. One of the two solutions cited in section 3 is basically a lexical approach which refers to the two types of verbs with the feature $[ \pm$ directional]. However, trying to redefine the binding domains within the original framework is problematic. Therefore we need to look at other frameworks that take a lexical approach. One of such frameworks is Lexical Functional Grammar (LFG). In this section, I first show how a lexical approach to binding is done in LFG by introducing Dalrymple's (1993) study on anaphors. Then I illustrate how control is handled in LFG. My proposal is based on a comparison between control and example (1), albeit with modifications.

Dalrymple (1993) studies anaphors in many different languages, primarily Marathi and Norwegian. The key fact is that in many languages there is more than one form of anaphor and each form comes with a set of unique constraints on anaphoric binding.

For example, in Norwegian "seg selv" and "ham selv" are both reflexives. But "seg selv" must be bound by a subject. In (17a), both "seg selv" and the subject DP "Jon" are in the same clause, and "seg selv" has to be bound by the subject DP "Jon". In (17b), if the DP "Jon" is not in a subject position, then the sentence is not grammatical. To be more specific, Dalrymple (1993: 34) describes the constraint as being bound to the "Subject in coargument domain".

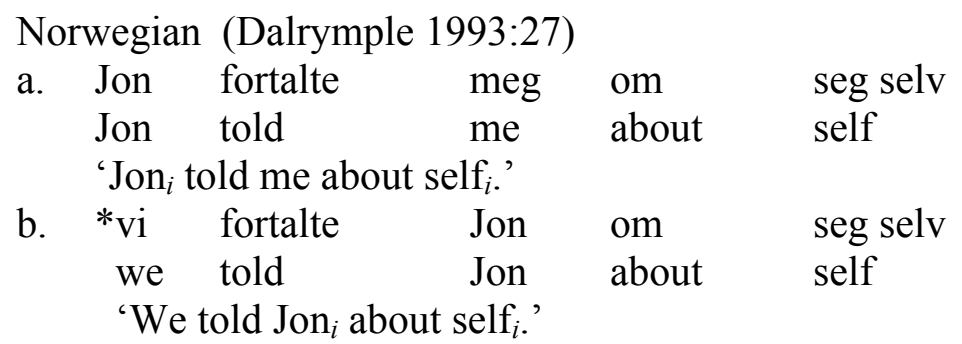

On the other hand "ham selv" must not be bound to a subject DP. In (18a), the reflexive "ham selv" cannot be bound by the subject DP "Ola". In (18b), if the DP "Ola" is not in the sub- 
ject position, then the binding relations between "Ola" and "ham selv" is fine. To be more specific, Dalrymple (1993:34) describes the constraint as being disjoint from "Subject in minimal complete nucleus", and being bound to an "Argument in minimal complete nucleus".

$$
\begin{aligned}
& \text { Norwegian (Dalrymple 1993:93) }
\end{aligned}
$$

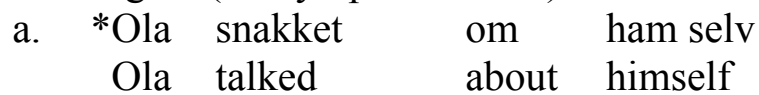

$$
\begin{aligned}
& \text { 'Ola }{ }_{i} \text { talked about himself } i . \text { ', } \\
& \text { b. vi fortalte Ola om ham selv } \\
& \text { we told Ola about himself } \\
& \text { 'We told } \mathrm{Ola}_{i} \text { about himself }{ }_{i} \text {.' }
\end{aligned}
$$

In light of such data, it becomes clear now that anaphoric binding may be envisaged differently by looking at the constraints and lexical items separately. On the one hand there is a set of universally available constraints on anaphoric binding, and on the other hand, different lexical items may select a combination of different constraints. For example, Bresnan, Halvorsen and Maling (1985) propose the following constraints that can be specified in the lexicon.
(19) Lexically-specified constraints (Bresnan et al. 1985, cited by Dalrymple 1993:92)
- SUUJ $_{\text {SUB }} \quad$ Bound by/free from a SUBJ
- +NUClEAR Bound in the minimal complete nucleus
- -NUCLEAR Free in the minimal nucleus

According to Dalrymple (1993:92), "The SUBJECT feature indicates whether a lexical item has a subject as its antecedent." Thus it seems quite straightforward that the Norwegian "seg selv" is +SUBJECT, while the Norwegian "ham selv" is -SUBJECT. The other two constraints are similar to the binding domains. For example, the English reflexive is +NUCLEAR, while English pronouns are-NUCLEAR.

Now with these constraints in mind, looking back at example (1) and example (5), the pronoun in (1) clearly can be characterized by -SUBJECT and -NUCLEAR, while the pronoun in (5) is -NUCLEAR. However this solution cannot be right. In contrast to the Norwegian examples where there are two reflexives which have different constraints in their lexical entries, in the Chinese examples in (1) and (5), there is exactly just one and the same pronoun "tā", and if we give two different lexical entries with two different sets of constraints for the same word "tā", we are creating a new problem, i.e. which lexical entry should be selected. Certainly this can be solved by adding a further stipulation that [+directional] verbs should select the lexical entry for "tâ" that contains -SUBJECT and-NUCLEAR as its constraints, while [-directional] verbs should select the lexical entry for "tā" that contains just-NUCLEAR. Now we are multiplying the level of complexity in our solution. Moreover the real problem is that there is indeed just one word "tā", and there should not be two different lexical entries for it.

If we compare the Chinese examples in (1) and (5) to the Norwegian examples correctly, we should probably focus on the verbs rather than the pronoun, because there are two subcategories of verbs that clearly select different constraints for the binding relations in the sentences. Now a possible solution is to simply add the constraints to the lexical entries for the two types of verbs. For each embedding verb in the lexicon, there should be more specific information regarding binding relations. For example, for the lexical entry of "gănxiè", it should include -SUBJECT and-NUCLEAR in its lexical specification. Note that since we have these two constraints already, we do not need the [+directional] any more, at least not for the purpose of solving the problems 
with regard to the binding relations. The [-directional] verbs will be picked out by their different sets of constraints. This solution seems straightforward, but how are such lexically-specified constraints interpreted in the LFG framework both syntactically and semantically? These constraints are originally specified for anaphors and pronouns and they can be projected onto the fstructures in LFG, and from the f-structures onto the semantic or $\sigma$ structures. If we put these constraints into the lexicon for the verbs, it is not quite clear yet how these constraints could be projected from the verbs to relevant $\mathrm{f}$-structures that will have the information from the related pronouns and DPs, and eventually to the $\sigma$ structures. Therefore it seems that to use these constraints for the verbs does not work either. We need to find another solution.

Now let's look back at the contrast between example (1) and example (14), repeated here slightly modified as (20) and (21) respectively.

(20) Mandarin Chinese (Shen and Dong 2004: 21)

Xiăo Wáng gănxiè tā zuò de duì

Xiao Wang thank he do COMP correct

'Xiao Wang $_{i}$ thanks that he $*_{i j}$ did the right thing.'

$\begin{array}{lllll}\text { Xiăo Wáng ràng tā } & \text { zuò } & \text { gōngkè } \\ \text { Xiao Wang ask he do } & \text { homework } \\ \text { 'Xiao Wang }{ }_{i} \text { asks him }{ }^{*} i j \text { to do homework.' } & \end{array}$

Although in (20) there is a finite embedded clause, and there is no PRO, while in (21) there is a non-finite embedded clause and there is a PRO in the subject position of the embedded clause, we still find that basically the two structures look quite similar on the surface if we temporarily ignore the PRO in the example (21). Therefore a look at how control is handled in LFG will definitely help us to understand how to handle example (1).

Neidle (1994) discusses the following example of control.

Mary considers John [ PRO boring ].

Example (22) is a case of object control. The non-finite clause contains a PRO, and this PRO is controlled by the object DP "John". Such constraints can be nicely captured in the LFG framework via a control equation. For example, the lexical entry for the verb "to consider" would look like this:

Lexical entry for "consider" (Neidle 1994, with some modifications here)

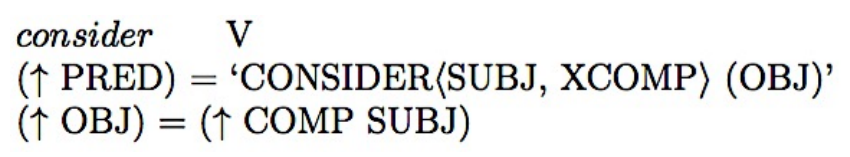

In (23), the symbol XCOMP indicates that there are different types of complements that the verb can take. For example, instead of saying "Mary considers John boring", we can say "Mary considers John a brilliant scholar". The symbol PRED refers to the meaning of the verb. The symbols SUBJ and OBJ are more self-explanatory. The up arrow symbol $\uparrow$ is a variable that refers to the lexical item under which the information is found. The line " $(\uparrow \mathrm{OBJ})=(\uparrow \mathrm{XCOMP}$ SUBJ)" is where the control equation is specified. It says that the object of the verb should be the same as the subject of the complement clause. This equation can be readily projected to an $\mathrm{f}$ structure. In Figure 1, the null subject of the complement clause is co-indexed with the object of the verb "consider". This information is derived from the control equation in (23). This achieves the same result as the control theory in other formal frameworks. Alternatively, co-indexing is 
also commonly replaced by a line or an arrow that links these two items, as shown in Figure 2 . Note that in LFG there is also the c-structure that goes hand-in-hand with the f-structure. But for our purposes here, the c-structure is not quite essential, and therefore I will omit the c-structures in my illustrations.

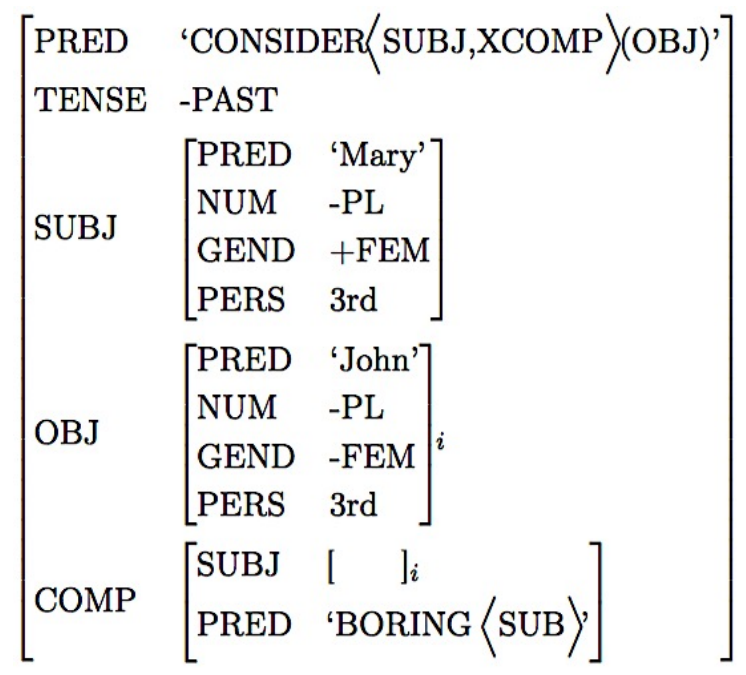

Figure 1. F-structure of a control verb, with indexing (modified from Neidle 1994)

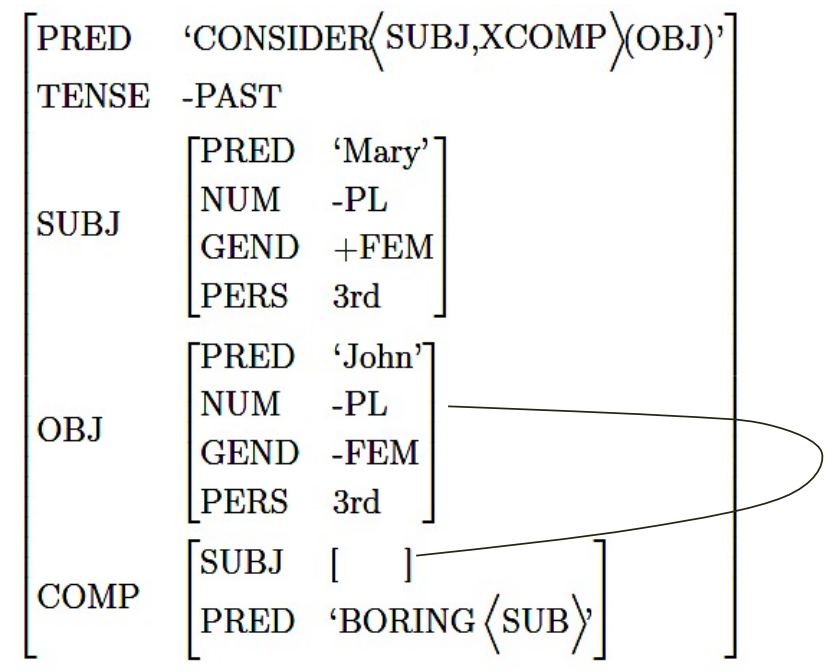

Figure 2. F-structure of a control verb, without indexing (modified from Neidle 1994)

This approach is indeed quite promising. We may very well model our solution to example (1) on example (22). Let's consider the following example, which is essentially the same as (1).

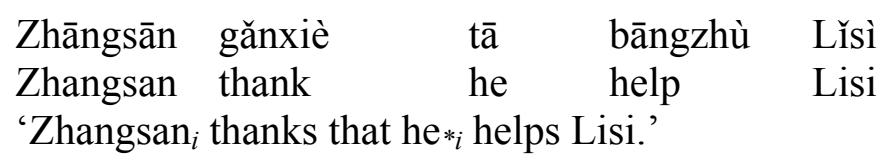

In example (24), it is the same verb "gănxiè", and the embedded pronoun in the subject position "tâ" cannot be bound by the matrix subject DP "Zhāngsān". In order to capture this binding constraint, I propose the following lexical entry for the verb "gănxiè". 
$(\uparrow$ PRED) $=$ 'THANK $\langle$ SUBJ, COMP $\rangle$ '

$(\uparrow \mathrm{SUBJ}) \neq(\uparrow \mathrm{COMP}$ SUBJ $)$

Although (25) looks very much the same as (23) in most of its details, there is one crucial difference. In (23), the control equation is expressed via an equality relation, while here in (25) it is an inequality relation, i.e. ( $\uparrow \mathrm{SUBJ}) \neq(\uparrow \mathrm{COMP}$ SUBJ $)$, which basically specifies that the subject of the verb cannot refer to the same entity as the subject of the complement clause. Because the constraint in example (1) and example (24) is a negative constraint in contrast to the control structure in (22), the substitution of the inequality symbol is justified. Now the lexical information in (25) can be projected to an f-structure such as in Figure 3.

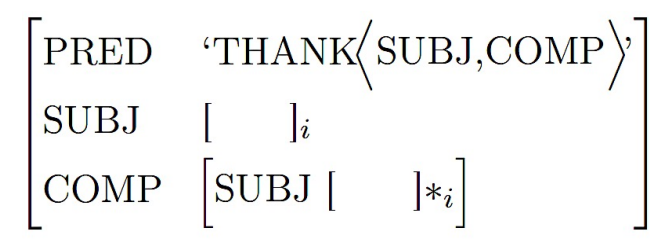

Figure 3. F-structure for the verb "gănxiè"

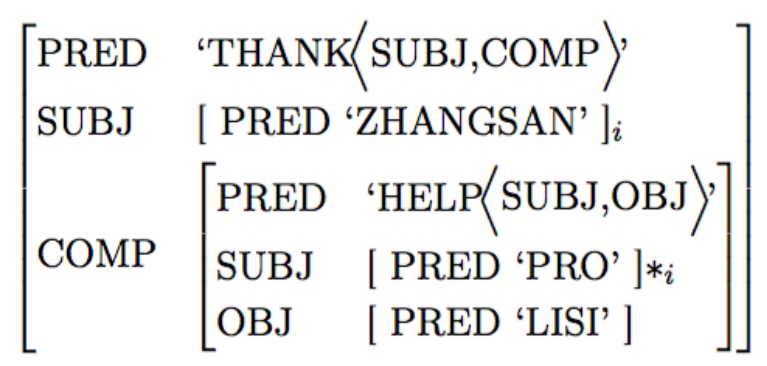

Figure 4. F-structure of example (24)

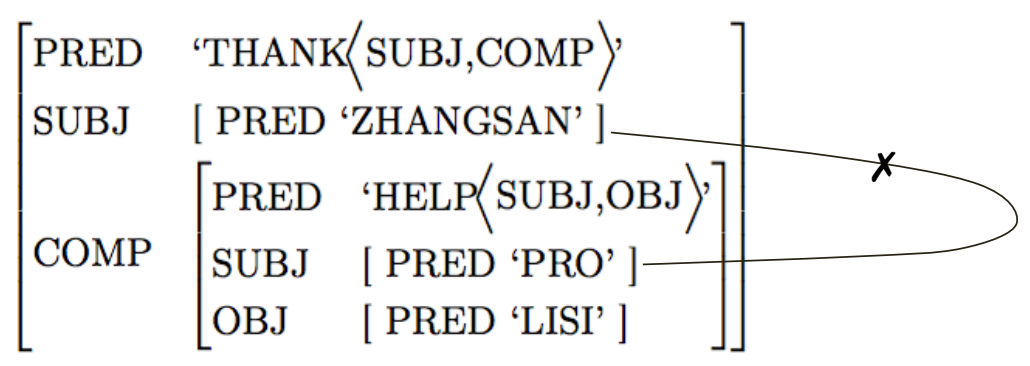

Figure 5. Alternative f-structure of example (24)

By filling in the lexical information from the argument DPs, we can derive the f-structure for the whole sentence in (24) as shown in Figure 4. In contrast to the f-structure in Figure 1, here in Figure 4, the co-indexing is blocked, and this is where the inequality relation in (25) is projected. In Figure 4, the symbol "PRO" stands for "pronoun" and it is not the same as the PRO in control theory in other frameworks of formal syntax. As I have shown, verbs like "gănxiè" take a finite clause, and it is not a control verb. Alternatively Figure 5 replaces the indices with a line with an $x$ to block the binding relation. Moreover in both Figure 4 and Figure 5, I omit the information that is not relevant here, e.g. tense, number, gender and etc. 
I only discuss how example (1) can be accounted for in LFG by resorting to the inequality relation. Example (14) is a control structure, and it can be readily explained via the same control equation as in (23). As for example (5) with the verb "zhīdào", it does not need to be specially accounted for since it does not pose any theoretical issues at all, and in the lexical entry for the verb "zhīdào" there is simply no information regarding the equality or inequality relations.

To sum up this section, I first focus on the fact that example (1) should be accounted for from a lexical perspective, and then based on how anaphors are accounted for from such a lexical perspective, I experiment with two straightforward solutions to incorporate the various constraints described by Dalrymple (1993). But these solutions are ultimately rejected because of incompatibility of these constraints with the verbs, and uncertainty of how to project such constraints to the corresponding f-structures and possibly even the $\sigma$ structures. Then I go back to the contrast between example (1) and example (14) and focus on the surface similarity between them, although their syntactic structures are totally different. A new solution based on how control relations are handled in LFG via a control equation is proposed. The new solution uses the inequality relation instead of the equality relation and the projection to the f-structures correspondingly contain blocked indexing or blocked arrows. This new solution is by far the most straightforward one that gives the correct explanation of the binding relations in cases like example (1). I will discuss the advantages of this solution in more detail in the next section and then point out some directions for further research.

5. Conclusion. The new proposal that I make in section 4 based on the LFG control equation has three major advantages, both in terms of theory and application.

The first advantage is that compared to the other solutions it is the most economical. Now we have considered four major solutions to the theoretical challenges posed by example (1). The first solution proposed by Shen and Dong (2004) and Hu and Shi (2006) is to assimilate example (1) to control. But I have shown clearly that the embedded clause in example (1) is a finite clause and it does not contain a PRO. Therefore the first solution is ruled out.

The second solution, proposed by Dong (2002) and Shen and Dong (2004), posits two different binding domains and links the two subcategories of verbs with these two different domains by additional stipulations. But such a solution not only further complicates the situation but also contradicts the original motivation for the formulation of the Binding Principles based on the parallel properties or rather complementary distributions of anaphors and pronouns.

The third solution is the direct incorporation of a set of constraints in the lexical information for the verbs, modeled on Dalrymple's (1993) discussion of anaphors. But that solution is ruled out because of mismatch and interpretation difficulties.

The fourth solution is based upon the control equation in LFG, and it uses the inequality relation to block the co-indexing in the f-structure. Compared to all the other three solutions, this fourth solution is the most theoretically economical one because it only moves the information from the syntax to the lexicon without creating further stipulation to link the verbs to the selection of different lexical entries of pronouns.

But more importantly, the fourth solution is also compatible with the original versions of the Binding Principles or more appropriately, with the constraints introduced by Dalrymple (1993). For example, we may still keep the -NUCLEAR constraint in the lexical entry for the pronoun, and this corresponds to keeping the original Binding Principle B. The inequality relation information in the lexical entry of the verbs and the set of constraints in the lexical entry of pronouns can in fact work together harmoniously to derive the correct binding relations in a given 
sentence. This point is related to the second advantage of this fourth solution that I would like to turn to now.

The second advantage is that the lexicalized negative constraint helps with the resolution of pronominal co-reference since it immediately rules out one possibility. Combining this constraint with the usual structural constraint, e.g. Binding Principle B, or the kind of constraint proposed by Dalrymple (1993), which can rule out the co-indexing of the pronoun with the noun phrase within the same local clause, it can be quickly determined what the pronoun refers to. Let's take another look at example (24), which is repeated as (26) here.

$\begin{array}{llll}\text { Zhāngsān gănxiè } & \text { tā } & \text { bāngzhù } & \text { Lǐsì } \\ \text { Zhangsan thank } & \text { he help } & \text { Lisi } \\ \text { 'Zhangsan } & \text { thanks that he }{ }_{*}{ }_{i} \text { helps Lisi.' }\end{array}$

There are three possible indexing possibilities for the pronoun "tầ": Lǐsì, Zhāngsān, or someone else. As I have just pointed out above, we may still use the Binding Principle B here for the pronoun. The embedded clause is the binding domain and the pronoun should be free in this domain. Since the DP "Lǐsì" does not c-command the pronoun "tā", they cannot be co-indexed. Therefore the DP "Lissi" is ruled out as a binder. Alternatively if we use the -NUCLEAR constraint proposed by Dalrymple (1993), it can readily rule out the DP "Lǐsi”" without resorting to any structural relation such as c-command, since the pronoun and the DP "Lisì" are in the same nuclear clause, and they should not be co-indexed according to the -NUCLEAR constraint. Both approaches can equally rule out the DP "Lǐsi”" as a possible binder for the pronoun.

Next, the pronoun cannot be co-indexed with the matrix DP "Zhāngsān" either, according to the lexical constraint of the verb "gănxiè", as shown in Figures 4 and 5. Consequently the pronoun should be indexed with someone else in the discourse, determined by discourse factors.

This nicely captures both the fact that there is a constraint on pronominal binding in the lexical information of the pronoun and the fact that different verb subcategories affect the binding relations. These two types of information should both be specified somewhere in the grammar, either in the lexicon or in the grammar rules, and pronominal reference resolution will be much more well-informed within such a system.

The third advantage of this fourth solution is that it may very well be interpreted semantically via the linear logic system proposed by Dalrymple, Lamping, Pereira and Saraswat (1997). In a complete system, we need to get from the lexical information to the structural representation and ultimately to the semantic interpretation. It is not completely clear to me how this can be done within the standard formal syntax and semantics approach, e.g. the system in Heim and Kratzer (1998). Theoretically there is a way to do it in the formal semantics system. However, the linear logic system is more readily applicable here. With some modification, we can get from the lexical information to the c-structure and the f-structure, and then from the f-structure to the $\sigma$ structure, and this is a complete system. This will be one of the goals for further research.

The second goal for further research will be to extend this new solution to cover examples (2), (3) and (4). As I have pointed out, the grammaticality judgments with regard to examples (2), (3) and (4) are still not quite clear. If the conclusions of Dong (2002) and Shen and Dong (2004) are basically correct, the next step is certainly to figure out how these constraints can be formulated in a fashion similar to the lexical constraint here proposed for example (1). On the other hand if the conclusions of Hu and Shi (2006) are basically correct, then there is no need to extend our approach, because in examples (2), (3) and (4), it is possible to violate the kind of 
constraint described there, and therefore these cases can be accounted for by resorting to the Binding Principle B.

Furthermore there is another potential issue that might need to be addressed in more detail for further research. Although I point out in example (1) that it is not possible for the pronoun "tā" to co-refer with the subject DP, a reflexive, nonetheless, can be used to achieve this effect. The reflexive "zìji”" ("self") in (27) must be bound by the matrix subject DP "Xiăo Wáng", despite the slightly strange meaning of "thanking oneself". This is likely an instance of longdistance binding, as discussed by Huang and Tang (1991).

\begin{tabular}{|c|c|c|c|c|c|c|}
\hline Xiăo & Wáng $_{i}$ & gănxiè [IP & zìjī $\check{1}_{i / *_{j}}$ & zuò & de & \\
\hline Xiao & Wang & thank & self & do & COMP & correct \\
\hline
\end{tabular}

The pronoun "tā" and the anaphor "zìjì" do show a complementary distribution, because both have to be either bound or free in the matrix clause. In my solution proposed in (25), the inequality relation simply states that the subject of the complement clause cannot co-refer with the matrix subject DP, without regard to what kind of word the embedded subject DP is. If the embedded subject DP is an R-expression, such as a proper name, the constraint in (25) will still give the correct binding relations, because R-expressions should not be bound anywhere. But the same constraint will also rule out the co-indexing of "zìjī" with the matrix subject DP "Xiăo Wáng" in cases like (27). This is not a desired result of the proposed solution. For lack of a complete answer to this problem, I will sketch two possible answers that can be helpful for further research.

One possible answer is that somehow there should be a way to specify whether it is a pronoun or an anaphor within the proposed constraint and the LFG representations in this paper. If this can be done, then the constraint in (25) will not rule out the co-indexing between the anaphor and the subject DP, although it will still not require the co-indexing between the anaphor and the matrix subject DP. However this will not be a problem for my purpose here. Whatever solution has been proposed to account for long-distance binding should probably be helpful in ensuring such co-indexing in combination with the constraint introduced here.

The other possible answer is that we can simply add a global rule that anaphor must be bound within the maximal projection of the phrase structure. If the anaphor cannot be bound by anything within the immediate binding domain as usually defined, it has to find a potential binder within the next level up, and in this case it can find the subject DP as a binder. To say that this is a global rule, I mean that somehow it can over-rule the indexing elsewhere. Suppose that our constraint blocks the indexing between the anaphor and the subject DP. Now by checking the global rule we can over-write the original indexing and re-index the anaphor with the subject DP.

Whether either one of these two possible answers is correct will be the starting point for further research.

\section{References}

Bresnan, Joan. 2001. Lexical-Functional Syntax. Oxford: Blackwell.

Bresnan, Joan, Halvorsen, Per-Kristian, and Maling, Joan. 1985. Logophoricity and bound anaphors. Ms. Stanford University.

Büring, Daniel. 2005. Binding theory. New York: Cambridge University Press.

Chomsky, Noam. 1981. Lectures on government and binding. Dordrecht: Foris Publications.

Chomsky, Noam. 1986. Knowledge of language: Its nature, origin, and use. New York: Praeger. 
Dalrymple, Mary. 1993. The syntax of anaphoric binding. Stanford, CA: CSLI.

Dalrymple, Mary, Lamping, John, Pereira, Fernando, and Saraswat, Vijay. 1997. Quantifiers, anaphora, and intensionality. Journal of Logic, Language and Information, 6(3). 219-273.

Dong, Hongyuan (董红源). 2002. Hànyǔ Dàicí Tã de Jù Nèi Zhàoyìng Guīzé Yánjiūu 汉语代词 “他” 的句内照应规则研究 (“Studies in the Intra-sentential Co-reference Rules of the 3rd person pronoun 'ta' in Chinese”). MA Thesis, Peking University (北京大学中文系硕士论 文). Beijing, China.

Hsieh, Miao-Ling. 2002. Tense as a grammatical category in Chinese. In On the formal way to Chinese languages, edited by Sze-Wing Tang and Chen-Sheng Luther Liu. Stanford, CA: CSLI.

Hu, Jianhua (胡建华) and Shi, Dingxu (石定栩). 2006. Yuēshù B Yuánzé Yǔ Dàicí de Jù'nèi Zhǐchēng 约束 B 原则与代词的句内指称 (“Binding Principle B and the intra-sentential coreference of pronouns”). Zhōngguó Yǔwén 中国语文 (“The Journal of Chinese”) 2006:1, pp. 3-9, Beijing, China.

Huang, C.-T. James and Tang, C.-C. Jane. 1991. The local nature of the long-distance reflexive in Chinese, in Jan Koster and Eric Reuland (eds.), Long-distance anaphora, Cambridge University Press, Cambridge.

Heim, Irene and Kratzer, Angelika. 1998. Semantics in generative grammar. Wiley-Blackwell.

Lin, Jo-wang. 2006. Time in a language without tense: The case of Chinese. Journal of Semantics, 23(1), 1-53.

Neidle, Carol. 1994. Lexical Functional Grammar. In The Encyclopedia of Language and Linguistics. New York: Pergamon Press, 2147-2153. Reprinted in Keith Brown and Jim Miller (eds.) 1996. Concise Encyclopedia of Syntactic Theories. Oxford: Elsevier.

Reinhart, Tanya and Reuland, Eric. 1993. Reflexivity. Linguistic Inquiry, 24(4). 657-720.

Shen, Yang (沈阳) and Dong, Hongyuan (董红源). 2004. “Zhíjiē Tǒngzhì” Yŭ “Tā” de Jù’nèi Suǒzhǐ Guizzé “直接统制” 与 “他” 的句内所指规则 (“Direct c-command and the intrasentential co-reference rules of 3rd person pronoun "ta" in Chinese "). Zhōngguó Yǔwén 中 国语文 (“The Journal of Chinese”) 1. 16-29. Beijing, China. 